\title{
Anthropometric Analysis of the Nose
}

\author{
Abdullah Etöz \\ Aesthetic, Plastic and Reconstructive Surgery, Bursa \\ Turkey
}

\section{Introduction}

Anthropometric analysis is a method, aiming to achieve the most reliable comparison of the body forms by using specific landmarks determined in respect of anatomical prominences. Owing to the previous anthropometric studies, it is getting easier to discuss about the differences in between the ethnic and racial groups, and to compare the individual variations in both sexes. A great body of work in craniofacial anthropometry is that of Farkas who established a database of anthropometric norms by measuring and comparing more than 100 dimensions (linear, angular and surface contour's) (DeCarlo, 1998).

Today, anthropometric methods and surgical practice intersected at the point to treat congenital or post-traumatic facial disfigurements in various racial or ethnic groups successfully (Farkas et al 2005). The nose is a person's most defining feature because it is at the center of the face. The shape of the nose is a signature indicating the ethnicity, race, age and sex (Ofodile, 1995; Milgrim et al 1996; Mishima et al 2002; Ochi, 2002; Romo, 2003; Ferrario et al 1997; Bozkir et al 2004; Leong, 2004; Uzun et al 2006). Nasoplasty surgeons require access to facial databases based on accurate anthropometric measurements to perform optimum correction in both sexes.

There are several anthropometric studies related with the nose, which are bringing forward other different methods. However we decide to review a landmark-based geometric morphometric technique which can be easily used to analyze the nasal shapes in any population.

The shape differences in nasal anatomy between male and female are important thus, feminization of a male nose is an undesirable result. A successful outcome in rhinoplasty requires a thorough and accurate preoperative planning, and awareness of the morphological differences. Anthropometric analysis of nose is showing us a way to provide data which should contribute to satisfactory results of the cosmetic nasal surgery.

List of abbreviations used in the manuscript:

NHP: Natural head position

EDMA: Euclidean Distance Matrix Analysis

\section{Anthropometric measurements}

Anthropometric analysis of nasal anatomy is based on the comparison of measurements which are obtained separately from the anterior, lateral and inferior aspects. These measurements can be performed both by direct and indirect methods. Direct methods are 
time-consuming and have several other disadvantages such as difficulty of patient adaptation (especially in children and infants), problems concerning repeatability of measurements and archiving of data. Therefore, indirect measurement methods including photograph, cephalogram, stereophotograph, laser scanning, and computerized tomography have increasingly become popular in recent years. The most frequent methods used clinically are photogrammetry and cephalometry. Photogrammetry is a fast and inexpensive method with superior patient compliance. The most important disadvantage of two-dimensional photogrammetry is its inability to assess facial depth. Three-dimensional photogrammetry appears to be a more appropriate technique in this respect.

The following issues are crucial in anthropometric analysis of the nose:

1. Standardization of the method

2. Landmark identification

\subsection{Standardization of the method}

Details of standardization of the methods used in anthropometric analysis have previously been defined by several investigators and are beyond the scope of this review. It is important to note that a standard head position is essential for any facial measurement. Natural head position (NHP) is the most appropriate since it is the most reproducible and provides a natural face orientation for treatment planning.

\subsection{Landmark identification}

The accurate identification and reliability of the landmarks are the most important indicators of the accuracy of the anthropometric measurements. One way to increase accuracy is to mark the landmarks before measuring. Many soft tissue landmarks reflect underlying bony structure. The bony points must be palpated with a finger to find the soft tissue equivalent. While some soft tissue points can be marked with a dermographic pen, some soft tissue landmarks such as endocanthion, exocanthion, cheilion, and crista philtre can be clearly identified without palpation. In photogrammetry, meticulous identification of soft tissue landmarks and marking of the landmarks determined by inspection and palpation before the acquisition of photographs will certainly improve the reliability of measurements. Nasal landmarks are presented in Figure-1 and Table 1.

1-2: al, Alare, the point where the nasal blade (ala nasi) extends farthest out

3: sn, Subnasale, the midpoint of the columella base

4-5: $c^{\prime}$, Columella apex, the most anterior, or the highest point on the columella crest at the apex of the nostril

6: prn, Pronasale, the most prominent point on the nasal tip

* 7-8: The estimated junction of upper and lower lateral cartilages

9-10: $\mathrm{mf}$, Maxilloanteriorale, where the maxilloanterioral and nasoanterioral sutures meet

11: $\mathbf{n}$, Nasion, the point in the midline of both the anatomic nose and the nasoanterioral suture

Table 1. Anthropometric landmarks of nose from the anterior aspect. The numbers, abbreviations and definitions of the examined landmarks. The constructed landmarks are indicated by "*” sign 
* 1: the junction of nasolabial crease and nasal blade (ala nasi)

2: prn, Pronasale, the most prominent point on the nasal tip

3: sn, Subnasale, the midpoint of the columella base

4: al, Alare, the point where the nasal blade (ala nasi) extends farthest out

* 5: the most prominent point of medial cruris of alar cartilage

* 6: the most prominent point of lateral cruris of alar cartilage

7: $\mathbf{c}^{\prime}$, Columella apex, the most anterior, or the highest point on the columella crest at the apex of the nostril

* 8: The ending point of the nasolabial fold

* 9: The estimated junction of nasal and maxillary bones

* 10: The most prominent point of nasal dorsum (nasal hump)

* 11: The estimated insertion point of medial cantus

12: $\mathbf{n}$, Nasion, the point in the midline of both the anatomic nose and the nasoanterioral suture

Table 2. Anthropometric landmarks of nose from the lateral aspect. The numbers, abbreviations and definitions of the examined landmarks. The constructed landmarks are indicated by " ${ }^{\prime \prime \prime}$ sign

1-2: al, Alare, the point where the nasal blade (ala nasi) extends farthest out

3: sn, Subnasale, the midpoint of the columella base

* 4-5: The most convex point of lateral cruris of alar cartilage

6: prn, Pronasale, the most prominent point on the nasal tip

Table 3. Anthropometric landmarks of nose from the inferior aspect. The numbers, abbreviations and definitions of the examined landmarks. The constructed landmarks are indicated by "*” sign

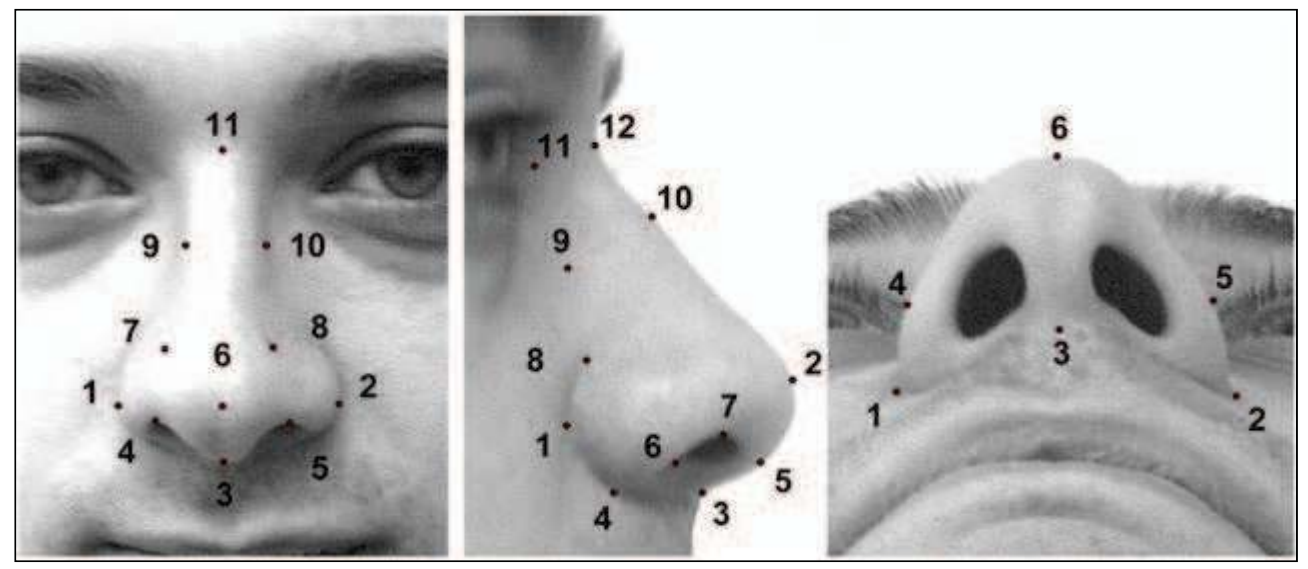

Fig. 1. Anthropometric (anterior 1-6, 9-11; lateral 2-4 and 12; inferior 1-3, 6) and constructed (anterior 7, 8; lateral 1, 5-11; inferior 4, 5) landmarks which were used in the anthropometric analysis of the nose 


\section{Key Point:}

Photogrammetry is an easier and more effective method for anthropometric analysis of the nose.

\begin{tabular}{|c|c|c|c|}
\hline & Anterior Aspect & Lateral Aspect & Inferior Aspect \\
\hline $\begin{array}{l}\text { The greater interlandmark } \\
\text { distances in males }(\mathrm{P}<0.05)\end{array}$ & $\begin{array}{l}2 Y 6,7 Y 8,2 Y 7,1 Y 3, \\
1 Y 6,2 Y 3, \\
1 Y 8,4 Y 5,1 Y 5,2 Y 4, \\
9 Y 10,1 Y 2\end{array}$ & $\begin{array}{l}\text { 4Y10, 6Y10, 8Y10, } \\
\text { 7Y9, 3Y9, 5Y11, } \\
\text { 5Y12, 3Y10, 7Y10, } \\
\text { 2Y11, 4Y6, 2Y12, } \\
\text { 3Y5, 4Y7, 5Y10, 5Y9, } \\
6 Y 7,2 Y 4, \\
6 Y 8,2 Y 9,2 Y 10,2 Y 6, \\
2 Y 7,3 Y 8, \\
1 Y 2,7 Y 8,9 Y 10,4 Y 5, \\
1 Y 7,2 Y 8, \\
1 Y 6,5 Y 8,1 Y 5,3 Y 6, \\
5 Y 6,1 Y 4, \\
3 Y 4,1 Y 3,5 Y 7,\end{array}$ & $\begin{array}{l}2 Y 3,3 Y 5,3 Y 4 \\
2 Y 4, \\
1 Y 3,1 Y 2,1 Y 5 \\
4 Y 5\end{array}$ \\
\hline $\begin{array}{l}\text { The greater interlandmark } \\
\text { distances in females }(\mathrm{P}< \\
0.05)\end{array}$ & $\begin{array}{l}\text { 4Y9, 3Y9, 1Y9, } \\
\text { 2Y10, 6Y9, 5Y10, } \\
\text { 3Y10, 6Y10, 7Y9, } \\
\text { 3Y11, 6Y11, } \\
\text { 8Y10, 4Y11, 5Y11, } \\
\text { 4Y7, 5Y8 }\end{array}$ & 1Y9, 1Y11, 8Y9, & $\begin{array}{l}3 Y 6,2 Y 5,2 Y 6 \\
1 Y 6,1 Y 4\end{array}$ \\
\hline
\end{tabular}

Table 4. The Inter-landmark Distances Found to be Significantly Different Between Males and Females. In figure 2 these interlandmark distances were shown by bold and thin lines

\begin{tabular}{|l|l|}
\hline Total length of nasal bridge & (n-prn) \\
\hline Morphological width of nose & (al-al) \\
\hline Nasal root width & (mf-mf) \\
\hline Anatomical width of nose & (ac-ac) \\
\hline Tip protrusion & (prn-sn) \\
\hline
\end{tabular}

Table 5. The common names for interlanmark distances of the nose 


\begin{tabular}{|l|c|c|c|c|}
\hline \multirow{2}{*}{} & \multicolumn{2}{|c|}{ Males } & \multicolumn{2}{c|}{ Females } \\
\cline { 2 - 5 } & $\mathbf{r}$ & $\mathbf{p}$ & $\mathbf{r}$ & $\mathbf{p}$ \\
\hline MorphologicNasal Width / Nasal Root Width & .616 & $<0.001$ & .345 & 0.001 \\
\hline MorphologicNasal Width / Length of nasal bridge & .651 & $<0.001$ & .409 & $<0.001$ \\
\hline Morphologic Nasal Width / Anatomical width of nose & .612 & $<0.001$ & .317 & 0.003 \\
\hline MorphologicNasal Width / Tip protrusion & .299 & 0.007 & .286 & 0.008 \\
\hline Nasal Root Width / Length of nasal bridge & .492 & $<0.001$ & .439 & $<0.001$ \\
\hline Nasal Root Width / Anatomical width of nose & .392 & $<0.001$ & - & $\mathrm{p}>0.05$ \\
\hline Nasal Root Width / Tip protrusion & .351 & 0.001 & - & $\mathrm{p}>0.05$ \\
\hline Length of nasal bridge / Anatomical width of nose & .410 & $<0.001$ & .223 & 0.039 \\
\hline Length of nasal bridge / Tip protrusion & .405 & $<0.001$ & .378 & $<0.001$ \\
\hline Anatomical width of nose/ Tip protrusion & .527 & $<0.001$ & .761 & $<0.001$ \\
\hline
\end{tabular}

Table 6. For example, the data showing us the statistical correlations of the interlandmark distances of nose in both sex

\section{Landmark reliability}

It is important to understand the various sources of error that can affect anthropometric measurements during location of landmarks. Lack of precision results in variability among repeated measurements of the same specimen and has two components:

- Observer error in locating landmarks

- Instrument error in identifying landmark coordinates (Lele, 1991 and 1993).

It is crucial to analyze the reliability of the landmarks. Optimal standard to achieve reliability is that all landmarks should be marked by the same investigator on all subjects. Instrumental errors should be avoided by using a standardized digital photographic imaging taken from anterior, lateral and inferior aspects by using a constantly stable digital camera (Hwang, 2003; Uzun et al 2006).

\section{Collection of two-dimensional craniofacial landmarks of nose}

The data collection procedure should take place in two separate steps, and followed by offline calculations. At first, for each subject, digital photographic images should be taken by the same investigator using an at least 2.0 mega pixel digital camera. At the second stage, the examined landmarks are marked on these digital images. Anthropometric landmarks are defined in Figure-1. The landmarks shown in the figure are also accepted in previous anthropometric studies (Farkas et al 1998). For enrichment of nasal anthropometric analysis, some "constructed" landmarks are also used. These landmarks are determined by constructing a line tangent to another landmark or a bony edge. The descriptions of the examined landmarks are done in Table 1 and shown in Figure 1.

For each subject, eleven landmarks (five anthropometric and two constructed) in the anterior aspect, twelve landmarks (four anthropometric and eight constructed) in the lateral aspect and six landmarks (four anthropometric and two constructed) in the inferior aspect of 
nose are defined. The landmarks were marked on the digital photographs by using TPSDIG 2.04 software. This software was developed by F. James Rohlf and it is one of the most frequently used software both for the marking the landmarks (however, what is recommended is to take photos after marking the landmarks on the person) and for determining the inter-landmark distances in pixels. A ruler is used in the shooting for the measurement of the distances between the landmarks in digital images and later on the unit distance $(1 \mathrm{~cm})$ is calibrated with its equivalent in pixel in order to obtain measurement values separately.

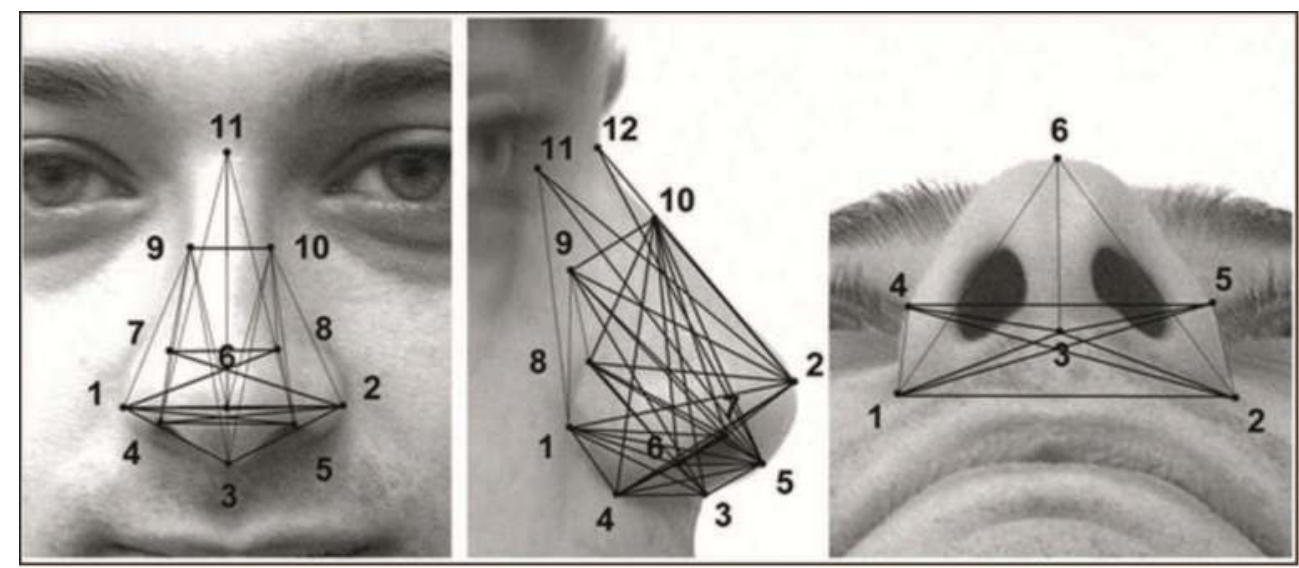

Fig. 2. The inter-landmark distances, viewed from anterior, lateral and inferior aspects. These distances could be measured by computer scales in photogrammetric computer programs and the results should be proportionate to each other. For example in this figure, the thin lines indicate the inter-landmark distances which were found to be greater in females; the bold lines indicate the inter-landmark distances which were found to be greater in males

It was proven to be reliable in studies including facial landmarks by Nechala (1999) and Ferrario et al (2003) which compared photogrammetry with direct measurements, and showed that sharp facial profile contours could eliminate the differences between the direct and indirect measurements of the nose. The strengths and limitations of photogrammetry must be appreciated. However, it is ideally suited to the evaluation of proportions, as the magnification factor is eliminated (Weigberg, 2005).

Statistical studies of anatomical shape variations in population are important in understanding anatomical effects of diseases or biological processes. Several procedures for obtaining shape information from landmark data have been proposed. Euclidean Distance Matrix Analysis (EDMA) is used to calculate all possible linear distances among landmarks by creating matrixes for each subject. EDMA results are actually related to the coordinatesystem-invariant properties that make EDMA biologically and statistically advantageous (Theodore, 1998).

Ethnic influences can result in different appearances of the nose, as follows: Caucasian, leptorrhine; African American, platyrrhine; Hispanic, paraleptorrhine; and Asian, subplatyrrine. For example, there are three types of African American noses are described: 
African, Afro-Caucasian, and Afro-Indian (Ofodile, 1995). There are also variations of nasal shape related to sex in both ethnic groups. Nose shape gives information about race, ethnicity, age and sex. The size, shape, and proportions of the nose provide a visual basis suggesting the character of the person. Moreover, it is an important key for a natural and aesthetically pleasing human face (Aung et al, 2000). Accordingly, concern about the nasal shape has recently increased; lots of people want to have rhinoplasty operations. Any surgeon who performs rhinoplasty must be keenly aware of the morphological differences in nasal anatomy between male and female. The planning of the cosmetic nasal surgery must take into consideration psychological aspects, differences in skin conditions, and anthropometric measurements.

There have been many methods on the anatomic evaluation of the nose and variations in different racial and ethnic groups however there is an easy and reliable way to analysis nose shape: Photogrammetric nasal analysis which is based on framework and thought to be a better way to examine the differences of nose according to conventional methods.

\section{Applications to other areas of health and disease}

Today, the anthropometric methods and surgical practice intersected at a point to treat the congenital or post-traumatic facial disfigurements in various racial or ethnic groups successfully. Rhinoplasty surgeons require access to facial databases based on accurate anthropometric measurements to perform optimum correction in both sexes. There should be some points to be brought to mind during the cosmetic nasal surgery for men because of different expectations, which is not technically different from the one for women. Anthropometric analysis is a step to clarify these important points and basement for enhancing the plans of the corrective surgery.

\section{Practical guidelines}

- The subjects have to be recruited from a population who has no noticeable nasal, facial disfigurement and no history of previous nasal or facial surgery .

- Demographic data obtained included age, place of birth, and parental heritage.

- The subjects are rested for 10 minutes before the photography.

- A constant, stable three-leg camera holder is used and all the subjects are positioned at the same distance from the camera.

- All data was obtained from standardized digital photographic images taken from anterior, lateral and inferior aspects by using a digital camera.

- Anthropometric landmarks were defined regarding a previous report of Farkas et al.

- For enrichment of shape analysis, some "constructed" landmarks can be used, meaning that the definition of the landmark is determined by constructing a line to another landmark or bony edge.

- $\quad$ The landmarks should be marked by the same investigator on the digital photographs by using a digital imaging software.

\section{Summary points}

- Statistical studies of anatomical shape variations in population are important in understanding anatomical effects of diseases or biological processes. 
- Anthropometric analysis of facial asymmetry is based on the comparison of homolog measurements that are obtained separately from the anterior, lateral and inferior aspects.

- Standardization of method, accurate identification of landmarks to be used in the measurements in nasal anthropometric analysis.

- Anthropometric analysis is a step to clarify these important points and basement for enhancing the plans of the corrective surgery.

\section{References}

Aung S.C. (2000) Br J Plast Surg 53: 109-116

Bozkir M.G. (2004) Surg Radiol Anat 26:212-219

DeCarlo D. (1998) An Anthropometric face model using variational techniques. 25th Annual Conference on Computer Graphics and Interactive Techniques. Appeared in Proceedings SIGGRAPH' 98, pp 67-74

Farkas L.G. (2005) J Craniofacial Surg 16: 615-646

Ferrario V.F. (1997) Cleft Palate Craniofac J 34:309-317

Ferrario V.F. (2003) Clin Anat 16:420-443

Hwang T-S, Kang H-S. (2003) Ann Anat 185:189-193

Lele S, Richtsmeier J.T. (1991) Am J Phys Anthropol 86:415-428

Lele S (1993) Math. Geol. 25:573-602

Leong S.C.L., White P.S. (2004) Clin Otolaryngol 29:672-676

Milgrim L.M. (1996) Arch Otolaryngol Head Neck Surg 122:1079-1086

Mishima K. (2002) Cell Tissues Organs 170: 198-206

Nechala P. (1999) Plast Reconstr Surg 103:1819-1825

Ochi K, Ohashi T (2002) Otolaryngol Head Neck Surg 126:160-163

Ofodile F.A., Bokhari F (1995) Ann Plast Surg 34:123-129

Romo T, Abraham M.T. (2003) Fac Plast Surg 19:269-277

Rohlf FJ. http:/ /life.bio.sunysb.edu/ee/rohlf/software.html

Theodore M.C. III, Richtsmeier J.T. (1998) Am J Phys Anthropol 107:273-283

Uzun A. (2006) Auris Nasus Larynx 33:31-35

Weinberg S.M., Kolar J.C. (2005) J Craniofac Surg 16(5):847-51 


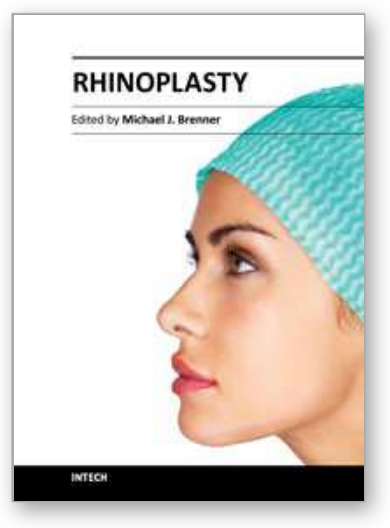

\author{
Rhinoplasty \\ Edited by Dr. Michael Brenner
}

ISBN 978-953-307-849-6

Hard cover, 146 pages

Publisher InTech

Published online 09, December, 2011

Published in print edition December, 2011

Rhinoplasty is one of the defining procedures of plastic and reconstructive surgery. Its roots stem from early efforts in nasal reconstruction to the emergence of modern rhinoplasty. This book describes the latest clinical and research perspectives in rhinoplasty and balances structural correction with aesthetic refinement. With treatises on rhinoplasty from a diverse set of thought leaders from around the world, the collective experience of this books' authors cover cosmetic and reconstructive approaches with a wealth of proven and innovative approaches ranging from minor refinement to major reconstruction. This diversity reflects the inherent complexity of the art and science of rhinoplasty. Discussion of structural approaches is balanced by consideration of judicious resection and refinement. The overarching goal is to instill an understanding of the subtleties of nasal structure and how the natural complexities of nasal anatomy can be adapted to maximize both function and natural appearance.

\title{
How to reference
}

In order to correctly reference this scholarly work, feel free to copy and paste the following:

Abdullah Etöz (2011). Anthropometric Analysis of the Nose, Rhinoplasty, Dr. Michael Brenner (Ed.), ISBN: $978-$ 953-307-849-6, InTech, Available from: http://www.intechopen.com/books/rhinoplasty/anthropometric-analysisof-the-nose

\section{INTECH}

open science | open minds

\author{
InTech Europe \\ University Campus STeP Ri \\ Slavka Krautzeka 83/A \\ 51000 Rijeka, Croatia \\ Phone: +385 (51) 770447 \\ Fax: +385 (51) 686166 \\ www.intechopen.com
}

\author{
InTech China \\ Unit 405, Office Block, Hotel Equatorial Shanghai \\ No.65, Yan An Road (West), Shanghai, 200040, China \\ 中国上海市延安西路65号上海国际贵都大饭店办公楼 405 单元 \\ Phone: +86-21-62489820 \\ Fax: +86-21-62489821
}


(C) 2011 The Author(s). Licensee IntechOpen. This is an open access article distributed under the terms of the Creative Commons Attribution 3.0 License, which permits unrestricted use, distribution, and reproduction in any medium, provided the original work is properly cited. 